Uluslararası Mühendislik

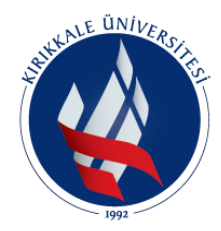
FAKÜLTESI Araştırma ve Geliştirme Dergisi UMAGD, (2022) 14(1), 316-321.

International Journal of

Engineering Research and Development

10.29137/umagd.1038160

Cilt/Volume:14 Sayı/Issue:1 Ocak/January 2022

Seçilmiş Konferans Makalesi / Selected Conference Article

\title{
Toz Metalurjisi ile Üretilen Cu-Al-Ni Alaşımlarında Yaşlandırma Süresinin Aşınma Davranışlarına Etkisi
}

\section{The Effect of Aging Time on Wear Behavior of Cu-Al-Ni Alloys Produced by Powder Metallurgy}

\author{
Doğan Şimşek ${ }^{1}$ iD
}

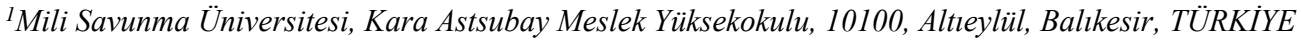

\author{
Başvuru/Received: 07/10/2021
}

Kabul / Accepted: 05/01/2022

Çevrimiçi Basım / Published Online: 31/01/2022

Son Versiyon/Final Version: 31/01/2022

\section{$\ddot{O} \mathbf{z}$}

$\mathrm{Bu}$ çalışmada, mekanik alaşımlama yöntemi ile üretilen $\mathrm{Cu}-\mathrm{Al}-\mathrm{Ni}$ alaşımlarında (nikel alüminyum bronzu) yaşlandırma süresinin aşınma davranışları üzerine etkisi incelenmiştir. Mekanik alaşımlanmış tozlar soğuk preslenerek (600 MPa) Ø10x6 mm boyutlarında ham numuneler üretilmiştir. Üretilen ham numuneler $950{ }^{\circ} \mathrm{C}$ sicaklıkta $60 \mathrm{dk}$ sinterlenerek firın ortamında oda sıcaklığına soğutulmuştur. Sinterlenen numuneler $900{ }^{\circ} \mathrm{C}$ sıcaklıkta 8 saat solüsyona alındıktan sonra suda hızlı soğutulmuştur. Yaşlandırma işlemleri $500^{\circ} \mathrm{C}$ sıcaklıkta $20 \mathrm{dk}, 60 \mathrm{dk}$ ve $80 \mathrm{dk}$ süre ile yapılmıştır. Yaşlandırma işlemi sonrasında standart metalografik çalışmalar yapılarak mikroyapı, sertlik ve yoğunluk ölçümleri yapılmışıı. Aşınma testlerinde $2 \mathrm{~ms}^{-1}$ kayma hızı, 2 farklı yük $(25 \mathrm{~N}$ ve $50 \mathrm{~N})$ ve 4 farklı kayma mesafesi $(250 \mathrm{~m}, 500 \mathrm{~m}, 750 \mathrm{~m}$ ve $1000 \mathrm{~m})$ kullanılmıştır. Yapılan çalışmalar sonucunda maksimum sertlik $60 \mathrm{dk}$ yaşlandırılan alaşımda $228 \mathrm{HV}$ olarak elde edilmiştir. Yoğunluk sonuçlarında ise artan yaşlandırma süresiyle yoğunlukta azalma meydana gelmiş ve en düşük yoğunluk değeri $60 \mathrm{dk}$ yaşlandırılan alaşımda $\left(6,08 \mathrm{gr} / \mathrm{cm}^{3}\right)$ olarak ölçülmüşsür. Aşınma testi sonuçlarında, en düşük ağırlık kaybı $60 \mathrm{dk}$ yaşlandırılan alaşımda elde edilirken, en yükssek ağırlık kaybının 80 dk yaşlandırılan alaşımda elde edilmiştir.

\section{Anahtar Kelimeler}

"Cu-Al-Ni alaşımı, yaşlandırma, toz metalurjisi, aşınma"

\begin{abstract}
In this study, was investigated the effect of aging time on wear behavior $\mathrm{Cu}-\mathrm{Al}-\mathrm{Ni}$ alloy (nicel aluminum bronze) produced by mechanical alloying method. Mechanical alloying powders were produced cold pressed (600 MPa) and green compacts of Ø10x6 $\mathrm{mm}$ dimensions. The produced green compacts were sintered at $950{ }^{\circ} \mathrm{C}$ for $60 \mathrm{~min}$ and cooled to room temperature in the furnace environment. Sintered samples were taken to the solution at $900{ }^{\circ} \mathrm{C}$ for 8 hours and then cooled rapidly in water. Aging processes were carried out at $500{ }^{\circ} \mathrm{C}$ for $20 \mathrm{~min}, 60 \mathrm{~min}$ and $80 \mathrm{~min}$. After aging, standard metallographic studies done and microstructure, hardness and density were measured. In wear tests were used $2 \mathrm{~ms}^{-1}$ sliding speed, 2 different loads $(25 \mathrm{~N}$ and $50 \mathrm{~N})$ and 4 different sliding distance $(250 \mathrm{~m}, 500 \mathrm{~m}, 750 \mathrm{~m}$ and $1000 \mathrm{~m})$. As a result of the studies, the maximum hardness was obtained as $228 \mathrm{HV}$ in the alloy aged $60 \mathrm{~min}$. In the density results, the density decreased with increasing aging time and the lowest density value was measured as $\left(6.08 \mathrm{gr} / \mathrm{cm}^{3}\right)$ in the alloy aged for $60 \mathrm{~min}$. In the wear test results, while the lowest weight loss was obtained in the alloy aged $60 \mathrm{~min}$, the highest weight loss was obtained in the alloy aged $80 \mathrm{~min}$.
\end{abstract}

\section{Key Words}

"Cu-Al-Ni alloy, aging, powder metallurgy, wear" 


\section{Giriş}

Bileşiminde \%9-12 alüminyum ve \%6 ya kadar demir ve nikel içeren bakır alaşımları ticari Cu-Al-Ni alaşımlarının (nikel alüminyum bronzlarının) önemli bir grubudur. Bu alaşımlar özellikle yüksek mukavemeti ve iyi sönümleme kapasitesine (çeliğe kıyasla iki kat daha fazla) sahiptir. Bununla birlikte bu alaşımlar iyi korozyon ve aşınma direnci gösterir. $\mathrm{Cu}-\mathrm{Al}-\mathrm{Ni}$ alaşımlarının sağladığı bu üstün özellikleri nedeniyle sınıfındaki en kullanışlı mühendislik malzemelerinden biri yapmaktadır (Yaseen vd. 2018). Cu-Al-Ni alaşımları havacılık denizcilik ve petrol endüstrilerinde yaygın kullanım alanları bulmaktadır. Cu-Al-Ni alaşımları havacılık sektöründe iniş takımı (Yaseen vd. 2018), denizcilik sektöründe gemi pervaneleri, pompalar ve valfler (Şimşek vd., 2020), petrol ve gaz endüstrilerinde kıvılcım çıkarmayan aletler, vanalar (Richardson, 2016) gibi farklı uygulamalarda yaygın kullanım alanları bulmaktadır. $\mathrm{Cu}-\mathrm{Al}-\mathrm{Ni}$ alaşımı üretiminde klasik döküm yöntemleri yaygın olarak kullanılmaktadır. $\mathrm{Cu}-\mathrm{Al}-\mathrm{Ni}$ alaşımları çok fazlı alaşımlar olduğundan 1sıl işlemlere uygundur. Literatürde $\mathrm{Cu}-\mathrm{Al}-\mathrm{Ni}$ alaşımlarında 1 șl işlemlerin etkisini üzerine birçok araştırma bulunmaktadır. Jain ve Nigam (2013), yaptıkları bir çalışmada döküm yöntemiyle ürettikleri Cu-Al-Ni alaşımlarının farklı sıcaklık ve sürelerde çözeltiye alma ve yaşlandırma işlemi uygulamışlardır. Elde ettikleri sonuçlarda, alaşımın sertliği, döküme göre çözeltiye alma ve yaşlandırma işlemlerinden sonra arttı̆̆ını belirtmişlerdir. En yüksek sertliğin $400{ }^{\circ} \mathrm{C}$ sıcaklıkta 3 saat yaşlandırılan $\mathrm{Cu}-\mathrm{Al}-\mathrm{Ni}$ alaşımında elde ettiklerini belirtmişlerdir. Bununla birlikte, Yasees vd., (2018) yaptıkları bir çalışmada sıcak dövme Cu-Al-Ni alaşımlarının soğutma hızının mikroyapı ve tribolojik özelliklerine etkisini araştırmışlardır. Elde edilen sonuçlarda, fırında oda sıcaklığına soğutulan Cu-Al$\mathrm{Ni}$ alaşımlarının farklı parametrelerle 1sıl işlem uygulanan $\mathrm{Cu}-\mathrm{Al}$-Ni alaşımlarına göre daha iyi tribolojik özellik gösterdiğini rapor etmişlerdir.

Yapılan bu çalışmada, bir toz metalurjisi yöntemi olan mekanik alaşımlama (MA) yöntemiyle üretilen Cu-Al-Ni alaşımlarının farklı yaşlandırma sürelerinin sertlik ve tribolojik özelliklerine etkisinin belirlenmesi hedeflenmiştir.

\section{Malzeme ve Metod}

Çalışmada mekanik alaşımlama yöntemiyle üretilen Cu-Al-Ni alaşımlarının farklı sürelerde yaşlandırma işleminin sertlik yoğunluk ve aşınma davranışları incelenmiştir. Üretilen Cu-Al-Ni alaşımı (Al bronzu) \% ağırlıkça $82 \mathrm{Cu}, 10 \mathrm{Al}, 3 \mathrm{Fe}$ ve $5 \mathrm{Ni}$ kimyasal bileşimine sahiptir. Belirtilen kimyasal bileşime sahip tozların alaşımlama işlemi, atritör tipi mekanik alaşımlama cihazında 304-L paslanmaz çelik öğütme hücresinde yapılmıştır. Mekanik alaşımlama işlemi, $8 \mathrm{~mm}$ çapında paslanmaz çelik bilye, 10:1 bilye toz oranı, $\% 50$ kap doluluk oranı ve $120 \mathrm{dk}$ alaşımlama süresi kullanılmıştır. Alaşımlama işlemi argon atmosferinde yapılmıstır. Mekanik alaşımlanan tozlar tek yönlü hidrolik pres kullanılarak Ø10x6 mm boyutlarında $600 \mathrm{MPa}$ basınç altında soğuk preslenerek ham numuneler üretilmiştir. Presleme işlemi sonrasında numunenin kalıptan çıkarılırken hem kalıbın hemde numunenin olası hasarı önlemek için yağlayıcı olarak çinko stearat kullanılmıştır. Üretilen ham numuneler $950^{\circ} \mathrm{C}$ sıcaklıkta $60 \mathrm{dk}$ sürede sinterlenmiş ve firın içerisinde oda sıcaklığına soğutulmuştur. Sinterleme işleminin ardından $900^{\circ} \mathrm{C}$ sıcaklıkta 8 saat solüsyona alınan numuneler suda hızlı şekilde oda sıcaklığına soğutuluştur. Solüsyona alma işlemi sonrasında $500{ }^{\circ} \mathrm{C}$ sicaklıkta 3 farklı sürede $(20 \mathrm{dk}, 40 \mathrm{dk}$ ve $80 \mathrm{dk})$ yaşlandırma işlemi uygulanmıştır. Yaşlandırma işleminde belirlenen sıcaklıkta belirlenen süre bekletilen numuneler firın ortamında oda sıcaklı̆̆ına soğutuluştur. Yaşlandırma isıl işlemi sonrasında standart metalografi işlemiyle hazırlanan numuneler $5 \mathrm{gr} \mathrm{FeCl}_{3}, 50 \mathrm{ml} \mathrm{HCl}$, and 100 $\mathrm{ml} \mathrm{H}_{2} \mathrm{O}$ dağlayıcı ile yaklaşık 45-50 sn dağlanmıştır. Mikroyapı çalışmalarında MEIJI ML 7100 optik mikroskop kullanılmıştır. Ardından numunelerin sertlik ve yoğunluk ölçümleri yapılmıştır. Sertlik ölçümleri AFFRİ VRSD251 sertlik cihazında her gruptan 3 numuneden 5 farklı noktadan yapılmıştır. Sertlik ölçümlerinde $10 \mathrm{sn}$ süre ve $5 \mathrm{~N}$ yük kullanılmıştır. Sertlik ölçümleri merkezden dışa doğru sıralı olarak yapılmıştır. Yoğunluk ölçümleri Precisa XB200h yoğunluk ölçüm kiti kullanılarak Archimed prensibine göre yapılmıştır. Yoğunluk ölçümleri her gruptan 3 numuneden yapılmış ve ortalama değer kullanılmıştır. Aşınma testleri standart pin-ondisk aşınma test cihazında yapılmıştır. Aşınma testlerinde, $2 \mathrm{~ms}^{-1}$ kayma hızı, 2 farklı yük $(25 \mathrm{~N}$ ve $50 \mathrm{~N}), 4$ farklı kayma mesafesi $(250 \mathrm{~m}, 500 \mathrm{~m}, 750 \mathrm{~m}$ ve $1000 \mathrm{~m})$ kullanılıştır. Aşınma testleri öncesinde numune yüzeyleri $3 \mu \mathrm{m}$ elmas solüsyon ile parlatılmıştır. Aşınma testleri her gruptan 3 numunede tekrarlanmış ve ortalama değer alınmıştır. Karşılık diski olarak $230 \mathrm{~mm}$ çapında $25 \mathrm{~mm}$ kalınlığında Ç1040 malzemeden ısıl işlem uygulanmış 50 Rc sertliğe sahip disk kullanılmıştır. Testlere başlanmadan önce numune ve karşılık disk yüzeyi aseton ile temizlenmiştir. Aşınma testleri sonrasında aşınma yüzeyler incelenerek oluşan aşınma mekanizması belirlenmeye çalışılmıştır.

\section{Bulgular ve Tartışma}

Farklı sürelerde yaşlandırılan Cu-Al-Ni alaşımlarının optik mikroskop görüntüleri Şekil 1.'de verilmiştir 


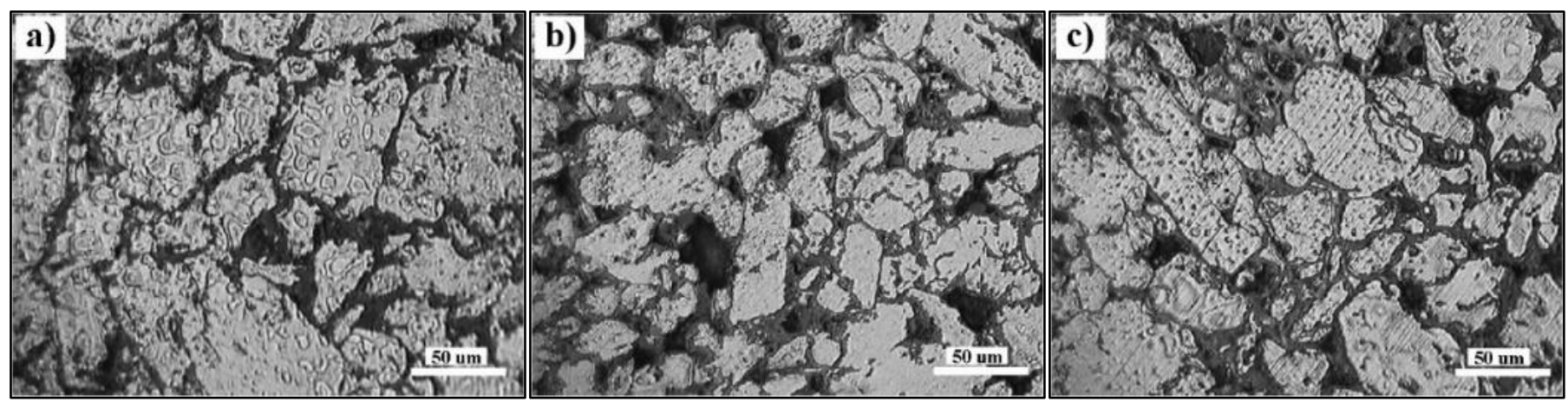

Şekil 1. Yaşlandırılan Cu-Al-Ni alaşımlarının optik mikroskop görüntüleri a) $20 \mathrm{dk}$ b) $60 \mathrm{dk}$ ve c) $80 \mathrm{dk}$

Şekil 1'de farklı sürelerde yaşlandırılan Cu-Al-Ni alaşımlarının optik mikroskop görüntüleri incelendiğinde, yapıda farklı bölgelerin (fazların) oluştuğu görülmektedir. Alaşımların yapısında 3 farklı bölgenin olduğu görülmektedir. Açık renkli bölgeler, koyu siyah bölgeler ve tane sınırlarında belirgin olan gri bölgelerdir. Şimşek vd. (2020), tarafından yapılan bir çalışmada mekanik alaşımlama üretilen al bronzu yapısında farklı bölgelerin olduğunu belirtmişlerdir. Bu bölgelerin ana alaşım elementi olan $\mathrm{Cu}$, $\mathrm{Fe}$ 'ce zengin bölgelerin ve Ni' ce zengin bölgelerin olduğunu belirtmişlerdir. Buna ek olarak Arifin vd., (2014), tarafından yapılan bir çalışmada ise $\mathrm{Fe}$ ' ce zengin bölgelerin genel olarak $\mathrm{Fe}_{3} \mathrm{Al}$ olduğu belirtilmiştir. Ayrıca Yaşar ve Altunpark (2009), bu alaşımlara $350{ }^{\circ} \mathrm{C}-560{ }^{\circ} \mathrm{C}$ sıcaklık aralığında yaşlandırılması ile martenzitik $\beta$ '- $\mathrm{CuAl}_{3}$ fazında $\gamma 2\left(\mathrm{Cu}_{32} \mathrm{Al}_{19}\right)$ parçacıklarının da çökelmesine yol açacağını belirtmiş̧lerdir. Farklı sürelerde yaşlandırılan Cu-Al-Ni alaşımlarının sertlik ve yoğunluk sonuçları Şekil 2'de verilmiştir.

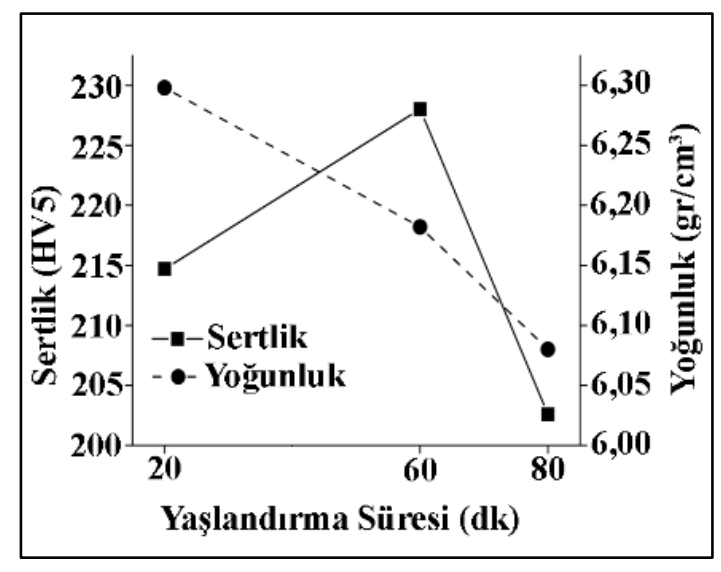

Şekil 2. Farklı sürelerde yaşlandırılan Cu-Al-Ni alaşımlarının sertlik ve yoğunluk sonuçları

Şekil 2'de verilen farklı sürelerde yaşlandırılan $\mathrm{Cu}-\mathrm{Al}-\mathrm{Ni}$ alaşımlarının sertlik sonuçları incelendiğinde, artan yaşlandırma süresi ile sertliğin arttığı görülmektedir. Yaşlandırma etkisi ile yapıda oluşan ikinci faz partiküllerinin dislokasyon hareketlerini engellemesi sertlik artışına neden olmaktadır (Simsek vd. 2019). Daha önce yapılan bir çalışmada alaşımların setlik değerinin yapıda oluşan Fe'ce ve Ni'ce zengin bileşiklerden kaynaklandığı belirtilmiştir (Sımsek vd.,2020). Ayrıca artan yaşlandırma süresi ile sertlik sonuçlarında tekrardan azalma olduğu görülmektedir. Sertlik ölçümü sonucunda değerlerdeki azalma, artan yaşlandırma süresiyle çökelti boyutlarının büyümesinden kaynaklandığı düşünülmektedir. Yaşar ve Altunpak, (2009) tarafından yapılan bir çalışmada artan yaşlandırma sıcaklığı ile sertliğin azaldığını bunun nedeninin malzemenin aşırı yaşlanma periyoduna geçmesinden kaynaklandığı bildirilmiştir. Şekil 2'de verilen yoğunluk grafiği incelendiğinde artan yaşlandırma süresiyle yoğunluğun azaldığı görülmektedir. Yoğunluk sonuçlarındaki bu azalma yapıda oluşan Fe ce zengin ikinci faz partiküllerinin oluşmasından kaynaklandığı düşünülmektedir. Artan yaşlandırma süresiyle yapıda oluşan $\mathrm{Fe}$ ve $\mathrm{Al}$ içeren bileşiklerin artması yoğunluk değerlerinin azalmasına neden olmaktadır (Sımsek vd.,2019). Farklı sürelerde yaşlandırılan Cu-Al-Ni alaşımlarının ağırlık kaybı ve aşınma oranı sonuçları Şekil 3'te verilmiştir. 


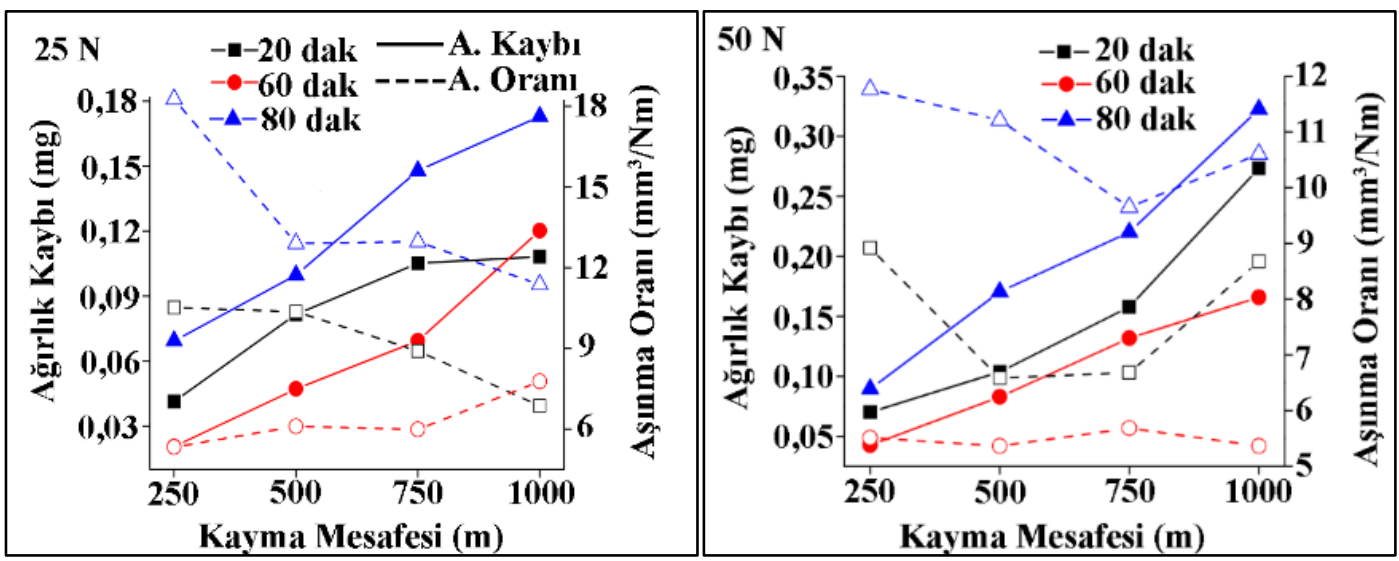

Şekil 3. Yaşlandırılan Cu-Al-Ni alaşımının farklı yükler altındaki ağırlık kaybı ve aşınma oranı sonuçları

Şekil 3'te verilen $25 \mathrm{~N}$ yükte elde edilen ağırlık kaybı sonuçları incelendiğinde bütün yaşlandırma sürelerinde artan kayma mesafesiyle ağırlık kaybının azaldığı görülmektedir. En yüksek ağırlık kaybı $80 \mathrm{dk}$ yaşlandırılan $\mathrm{Cu}-\mathrm{Al}-\mathrm{Ni}$ alaşımında elde edilirken en düşük ağırlık kaybı $60 \mathrm{dk}$ yaşlandıılan $\mathrm{Cu}-\mathrm{Al}-\mathrm{Ni}$ alaşımında elde edilmiştir. $50 \mathrm{~N}$ yük altında elde edilen ağırlık kaybı sonuçlarında da benzer durum söz konusudur. Yaşlandırma ile yapıda çökelen ikinci faz parçacıklar sertlik artışı sağlar bu da aşınma direncini artırmaktadır. Şekil 2'de verilen sertlik sonuçları ile ağırlık kaybı sonuçları birbirini desteklemektedir. Bilindiği gibi malzemelerin sertliğindeki artı̧̧ genel olarak aşınma direncini de artıırı (Özyürek ve Tekeli, 2010). $25 \mathrm{~N}$ yük altında elde edilen sonuçlarda $60 \mathrm{dk}$ yaşlandırılan $\mathrm{Cu}-\mathrm{Al}$ Ni alaşımının 1000m kayma mesafesinde ani bir ağırlık artışının olduğu görülmektedir. Ağırlık kaybındaki bu ani artış kayma esnasında numune yüzeyinden iri bir parçacığın kopmasından kaynaklandığı düşünülmektedir. Aynı alaşımın aşınma oranı sonucunda aynı kayma mesafesinde $(1000 \mathrm{~m})$ bu durumu desteklemektedir. Verilen grafiklerde aşınma oranı sonuçları incelendiğinde elde edilen aşınma oranlarının genel olarak azalma eğiliminde olduğu görülmektedir. $50 \mathrm{~N}$ yük altında elde edilen aşınma oranı sonuçlarında 20 ve $80 \mathrm{dk}$ yaşlandırılan $\mathrm{Cu}-\mathrm{Al}-\mathrm{Ni}$ alaşımlarında $750 \mathrm{~m}$ kayma mesafesine kadar aşınma oranlarının azaldığı görülürken $1000 \mathrm{~m}$ kayma mesafesinde aşınma oranlarında ani artışların olduğu görülmektedir. Kayma esnasında numune yüzeyinden kopan iri bir parçacık aşınma oranlarının ani olarak artmasına neden olmaktadır. $60 \mathrm{dk}$ yaşlandırılan $\mathrm{Cu}-\mathrm{Al}-\mathrm{Ni}$ alaşımında ise aşınma oranının daha düzlemsel bir şekilde olduğu görülmektedir. Aşınma oranlarındaki azalmalar kayma sırasında numune disk temas yüzeyinde açığa çıkan 1S1 etkisiyle oluşan koruyucu oksit tabakasının oluşmasından kaynaklanmaktadır (Sağlam, vd., 2011). Farklı sürelerde yaşlandırılan CuAl-Ni alaşımlarının farklı yükler altındaki sürtünme katsayıları Şekil 4’te verilmiştir.

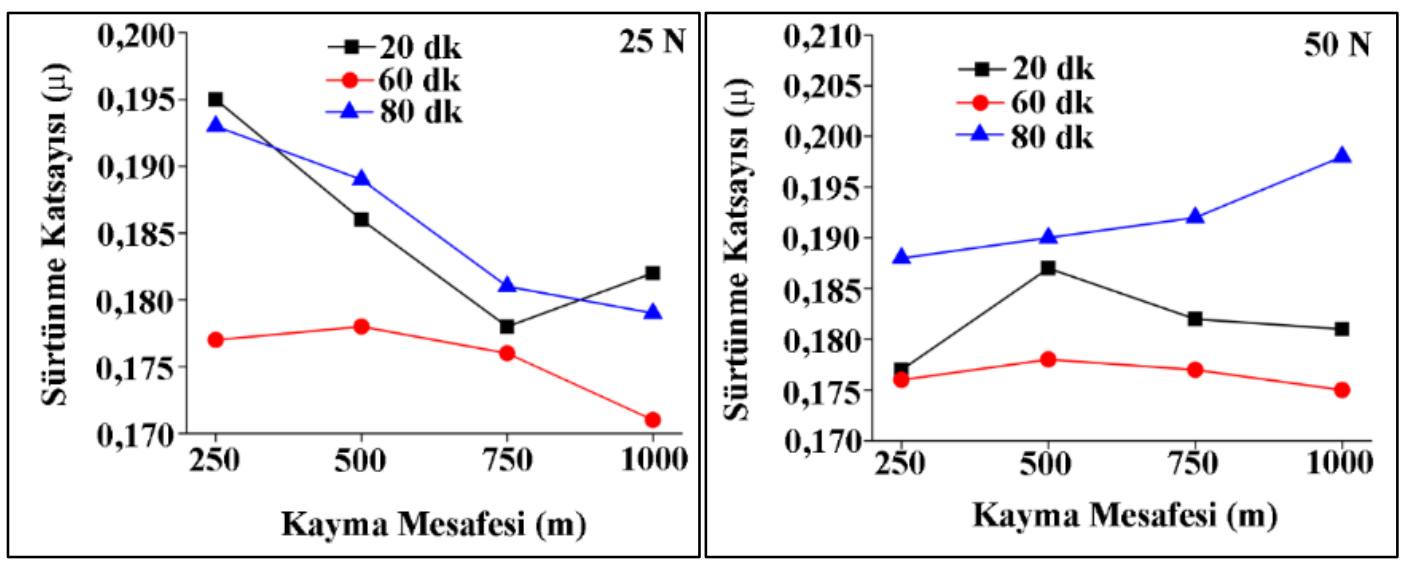

Şekil 4. Farklı sürelerde yaşlandırılan Cu-Al-Ni alaşımlarının farklı yük altındaki sürtünme katsayısı sonuçları

Şekil 4'te verilen farklı sürelerde yaşlandırılan Cu-Al-Ni alaşımlarının farklı yükler altındaki sürtünme katsayısı değişimleri incelendiğinde en yüksek sürtünme katsayısının kullanılan iki yükte de $(25 \mathrm{~N}$ ve $50 \mathrm{~N}) 80$ dk yaşlandırılan Cu-Al-Ni alaşımında elde edildiği görülmektedir. $25 \mathrm{~N}$ yük altında elde edilen sürtünme katsayısı sonuçları incelendiğinde sürtünme katsayılarının azalma eğiliminde olduğu görülmektedir. Sürtünme katsayılarındaki bu azalma, aşınma esnasında açığa çıkan 1sı etkisiyle numune yüzeyinde oluşan oksit tabakasından kaynaklandığı düşünülmektedir. Aynı yükte $20 \mathrm{dk}$ yaşlandırılan $\mathrm{Cu}-\mathrm{Al}-\mathrm{Ni}$ alaşımında $750 \mathrm{~m}$ kayma mesafesinden sonra sürünme katsayısında ani bir artışın olduğu görülmektedir. Kayma esnasında numuneden kopan mikro talaşların tribolojik sistemden uzaklaşamadan numune yüzeyine tekrardan yapışması (batması) sonucunda yüzey pürüzlülüğünün artması sürtünme katsayısınında artmasına neden olmaktadır. Yapılan yüzey pürüzlülüğü ölçümlerinde $20 \mathrm{dk}, 60 \mathrm{dk}$ ve $80 \mathrm{dk}$ yaşlandırılan alaşımların yüzey pürüzlülüğü sonuçları sırasıyla 2,632 Ra, 2,421 Ra ve 2,982 Ra olarak elde edilmiştir. Sekil 3 'te verilen ağırlık kaybı sonuçları incelendiğinde aynı numunenin 750 m kayma mesafesinden sonra ağırlık kaybı artışının yatay olarak ilerlemesi bu durumu 
desteklemektedir. Numune yüzeyine batan mikro talaşlar ağırlık kaybı azalmasına neden olurken yüzey pürüzlülüğünü artırarak sürtünme katsayısının artmasına neden olmaktadır. $50 \mathrm{~N}$ yük altında elde edilen sürtünme katsayısı sonuçlarında ise 60 dk yaşlandırılan $\mathrm{Cu}-\mathrm{Al}$ alaşımında sürtünme katsayısının azaldığı görülmektedir. Aynı yükte $20 \mathrm{dk}$ yaşlandırılan alaşımda ise $500 \mathrm{~m}$ kayma mesafesinde sürtünme katsayısının arttığı, artan kayma mesafesi ile tekrardan azaldığı görülmektedir. Aşınma testlerini ilk aşamasında numune disk temas yüzeyinde sürtünmeden kaynaklı oluşan kesme gerilmelerinden dolayı sürtünme katsayısı artmaktadır. Bununla birlikte artan kayma mesafesi ile sürtünme katsayısının azalması, numune disk temas yüzeyinde artan 1sı ile numune yüzeyinde oluşan koruyucu oksit film tabakasının katı yağlayıcı etkisinden kaynaklanmaktadır (Sımsek, vd., 2019). Farklı sürelerde yaşlandırılan Cu-Al-Ni alaşımlarının farklı yük altındaki aşınmış yüzey görüntüleri Şekil 5’te verilmiştir.
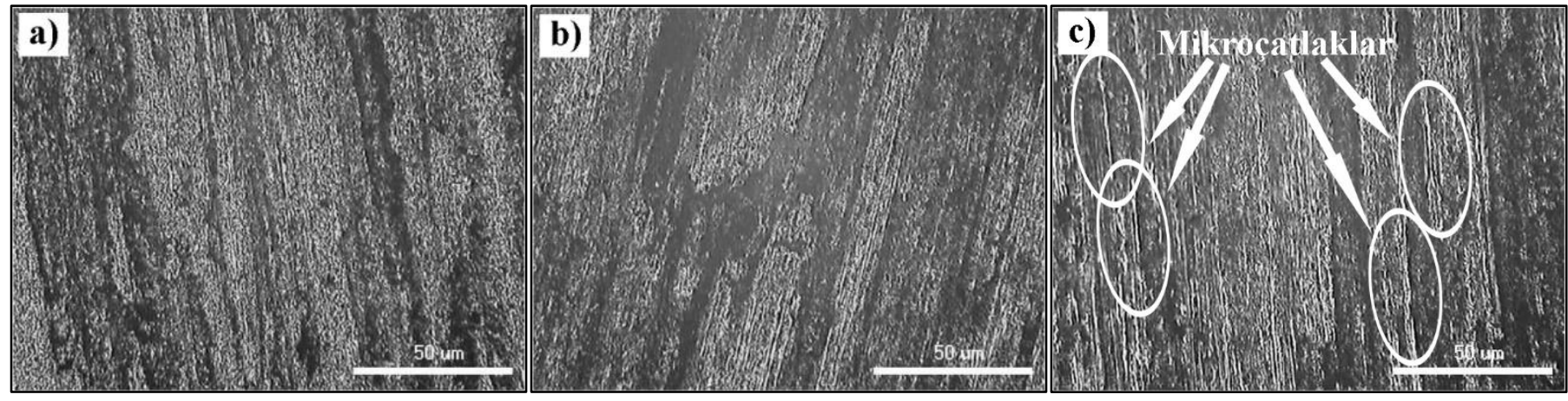

Şekil 5. Farklı sürelerde yaşlandırılan Cu-Al-Ni alaşımlarının $50 \mathrm{~N}$ yük altındaki aşınmış yüzey görüntüleri a) $20 \mathrm{dk}$ b) $60 \mathrm{dk}$ c) $80 \mathrm{dk}$

Şekil 5'te verilen farklı sürelerde yaşlandııılan $\mathrm{Cu}-\mathrm{Al}-\mathrm{Ni}$ alaşımlarının farklı yük altındaki aşınmış yüzey görüntüleri incelendiğinde kayma yönüne paralel aşınma çizgileri net olarak görülmektedir. $20 \mathrm{dk}$ yaşlandırılan $\mathrm{Cu}-\mathrm{Al}-\mathrm{Ni}$ alaşımının yüzeyinde yüzeye batan aşınma parçacıklarının (beyaz bölgeler) diğer numunelere göre daha fazla olduğu görülmektedir. Bu durum sürtünme katsayısı sonuçları ile uyumlu olduğu görülmektedir. Yüzeye batan aşınma parçacıkları, yüzey pürüzlülüğünü arttırarak sürtünme katsayısının artmasına neden olmaktadır. $60 \mathrm{dk}$ yaşlandırılan $\mathrm{Cu}-\mathrm{Al}-\mathrm{Ni}$ alaşımında ise numune yüzeyinde geniş düzlemsel yüzeylerin olduğu görülmektedir. Yaşlandırma süresinin artmasıyla numune yüzeyinde çatlak oluşumları da görülebilmektedir. Artan yüzey pürüzlülüğü ile numune yüzeyinde kesme gerilmesi bölgesel olarak alaşımın akma gerilmesini aşabilir. Alaşımın akma gerilmesini aşan kesme gerilmeleri yüzeyinde çatlak oluşumuna neden olmaktadır (Zhai, vd., 2017).

\section{Sonuçlar}

Toz metalürjisi yöntemi ile üretilen $\mathrm{Cu}-\mathrm{Al}-\mathrm{Ni}$ alaşımlarının yaşlandırma süresinin aşınma davranışları üzerine etkisinin incelendiği çalışmada elde edilen sonuçlar aşă̆ıda verilmiştir.

- Üretilen Cu-Al-Ni alaşımlarının mikroyapılarında farklı bölgelerin (fazların) oluştuğu görülmektedir.

- Yaşlandırılan alaşımların setlikleri yaşlandırma süresine bağlı olarak arttığı görülmüştür. En yüksek sertlik 60 dk yaşlandırılan alaşımda 228 HV olarak elde edilmiştir. Yaşlandırma süresinin $80 \mathrm{dk}$ olmasıyla sertliğin tekrardan azaldığı $(202 \mathrm{HV})$ görülmüştür.

- Farklı sürelerde yaşlandırılan $\mathrm{Cu}-\mathrm{Al}-\mathrm{Ni}$ alaşımlarının yoğunluklarının yaşlandırma süresinin artmasıyla azaldığı görülmüştür. En yüksek yoğunluk $20 \mathrm{dk}$ yaşlandırılan alaşımda $6,30 \mathrm{gr} / \mathrm{cm}^{3}$ elde edilirken, en düşük yoğunluk $80 \mathrm{dk}$ yaşlandırılan alaşımda 6,08 $\mathrm{gr} / \mathrm{cm}^{3}$ olarak elde edilmiştir.

- Farklı sürelerde yaşlandırılan alaşımların ağırlık kaybı sonuçlarında bütün yükler altında en düşük ağırlık kaybı 60 dk yaşlandırılan $\mathrm{Cu}-\mathrm{Al}-\mathrm{Ni}$ alaşımında elde edilirken en yüksek ağırlık kaybı $80 \mathrm{dk}$ yaşlandırılan $\mathrm{Cu}-\mathrm{Al}-\mathrm{Ni}$ alaşımında elde edilmiştir.

- Farklı sürelerde yaşlandırılan $\mathrm{Cu}-\mathrm{Al}-\mathrm{Ni}$ alaşımlarının aşınma oranı sonuçlarında en yüksek aşınma oranı $80 \mathrm{dk}$ yaşlandırılan alaşımda elde edilirken en düşük aşınma oranı $60 \mathrm{dk}$ yaşlandırılan alaşımda elde edilmiştir.

\section{Bilgilendirme}

Bu çalışma III. Uluslararası Savunma Sanayi Sempozyumu'nda sunulmuştur.

\section{Referanslar}

Arifin, A., Sulong, A. B., Muhamad, N., Syarif, J., ve Ramli, M. I. (2014). Material processing of hydroxyapatite and titanium alloy (HA/Ti) composite as implant materials using powder metallurgy: a review. Materials \& Design, 55, 165-175.

Jain, P., ve Nigam, P. K., (2013). Influence of heat treatment on microstructure and hardness of Nickel Aluminium Bronze (Cu-10Al5Ni-5Fe). IOSR Journal of Mechanical and Civil Engineering, 6(4), 16-21. 
Michler, T., ve Naumann, J., (2010). Influence of high pressure hydrogen on the tensile and fatigue properties of a high strength $\mathrm{Cu}-$ Al-Ni-Fe alloy. International Journal of Hydrogen Energy, 35(20), 11373-11377.

Özyürek \& Tekeli, S. (2010). An Investigation on Wear Resistance of SiCp-Reinforced Aluminium Composites Produced by Mechanical Alloying Method. Science and Engineering of Composite Materials, 17(1), 31-38.

Richardson, I. (2016). Guide to nickel aluminium bronze for engineers. Copper Development Association.

Sağlam, I., Özyürek, D., ve Çetinkaya, K. (2011). Effect of ageing treatment on wear properties and electrical conductivity of Cu-Cr$\mathrm{Zr}$ alloy. Bulletin of Materials Science, 34(7), 1465-1470.

Simsek, D., Colak, N. Y., Simsek, I., ve Ozyurek, D. (2020). Dry Sliding Wear Behaviors of Iron Addition to by Nickel-Aluminum Bronze Produced Mechanical Alloying. Transactions of the Indian Institute of Metals, 73(2), 319-326.

Simsek, I., Simsek, D., Ozyurek, D., ve Tekeli, S. (2019). The effect of the aging time on microstructure and mechanical properties of the AA7075 alloy after T6 heat treatment. Metallofizika Noveishie Tekhnology, 41(6), 817-824.

Torralba, J. D., Da Costa, C. E., ve Velasco, F. (2003). P/M aluminum matrix composites: an overview. Journal of Materials Processing Technology, 133(1-2), 203-206.

Vu, A. T., Nguyen, D. N., Mai, B. L., ve Mai, K. P. (2020). A study on the phase transformation of BCuAl9Fe4 alloy. International Journal of Modern Physics B, 34(22-24), 2040140

Yaşar, M., ve Altunpak, Y. (2009). The effect of aging heat treatment on the sliding wear behaviour of $\mathrm{Cu}-\mathrm{Al}-\mathrm{Fe}$ alloys. Materials \& Design, 30(3), 878-884.

Yaseen, M. K., Mansoor, M., Ansari, H. A., Hussain, S., ve Khan, S., (2018). Effect of heat treatment on tribological characteristics of CuAl10Ni5Fe4 nickel aluminum bronze. In Key Engineering Materials, 778, 61-67.

Zhai, W., Lu, W., Zhang, P., Zhou, M., Liu, X., ve Zhou, L., (2017). Microstructure, mechanical and tribological properties of nickelaluminium bronze alloys developed via gas-atomization and spark plasma sintering. Materials Science and Engineering: A, 707, 325336. 